$\mathrm{DOI}$

http://dx.doi.org/10.1590/2236-463320151007

Republicanism, Uncertainty and Morality in New Granada During the First Half of the Nineteenth century

\title{
República, tiempo incierto y moral en la primera mitad del siglo XIX neogranadino
}

\section{Francisco Ortega}

Universidad Nacional de Colombia, Bogotá - Cundinamarca, Colombia e-mail: faortegat@unal.edu.co

\section{Resumen}

En la primera mitad de este ensayo argumentaré que el colapso del régimen monárquico y la institución del sistema republicano a principios delsigloXIXdieron cabida en la región neogranadinaa una experiencia del tiempo que los mismos actores caracterizaron de precaria. En la segunda parte examinaré la respuesta intelectual a esa temporalidad precaria a partir de la obra de José Eusebio Caro (1817-53), filósofo, poeta, publicista y político neogranadino, uno de los fundadores históricos del partido conservador (1848), observador astuto-y escéptico-de las"revoluciones políticas y morales" de las repúblicas hispanoamericana y recurso ideológico de primer orden para el periodo llamado la Regeneración colombiana (1886-1930).

\section{Abstract}

In the first half of this article I will argue that the collapse of the monarchy (1810-1819) and the establishment of the republican system in the early nineteenth century gave way in New Granada (present day Colombia) to a new experience of time which contemporary actors characterized as precarious. In the second part I will examine the intellectual response to such precarious temporality by approaching the work of Colombian Jose Eusebio Caro (1817-1853), philosopher, poet, publicist and one of the historic founders of the Conservative Party (1848). Caro was an astute and skeptic observer of the "political and moral revolutions" of the Spanish American republics and became a primeideologicalresourceforColombianconservativesinthesubsequent period known as the Regeneration (1886-1930).

Palabras-chave

JoséEusebioCaro,Moral,República,republicanismo,PartidoConservador, Colombia, Historia de los Conceptos

Keywords

Jose Eusebio Caro, Morality, Republic, republicanism, Conservative Party, Colombia, History of Concepts 
El texto corresponde a una cita de las Memorias deBenjaminFranklinqueapareceen ellibroEssai surl'emploi du temps (Paris 1824) deM. A. Jullien. La cita apareció en el extracto del libro de Jullien queasuvezaparecióenel Repertorio Americano, tomo 1, página 168 (Londres 1827).

2

CARO, José Eusebio. La bendición nupcial. In: POMBO, Rafael (ed.). Obras escogidas en prosa y verso. Publicadas e inéditas. Bogotá: El Tradicionalista, 1873. p.47.

DUSO, Giuseppe. Historia conceptual como filosofía política. In: CHIGNOLA, Sandro; DUSSO, Giuseppe. Historia de los conceptos y filosofía política.Madrid:Editorial Biblioteca Nueva,2009. p.161.

4

CONSULTA de Doña Ángela Ysidra del Campo a Don Felipe de Vergara y su respuesta sobre si en Santafé de Bogotá será o no licito cenar la Nochebuena, y cenar buñuelos y pescado. Transcripción del manuscrito por María del Rosario Aguilary Perdomo.Bogotá:InstitutoCaro y Cuervo, 1993. p.49.

5

Aunque diversos autores han remarcado este fenómeno,ReinhartKoselleckelaboródemanera sistemática la existencia de una temporalidad tradicional y una de corte moderno, que emerge a finales del siglo XVIII. Ver, por ejemplo, KOSELLECK, Reinhart. historia/Historia. Madrid: Editorial Trotta, 2004. Aunque en las páginas siguientes no me referiré explícitamente a su elaboración teórica, buena parte de mi argumentacióndependedeella.Desarrolléparte de estas ideas en el ensayo, Tiempo precario y república en el siglo XIX colombiano. In: FERNÁNDEZ SEASTIÁN, Javier; SUÁREZ CABAL, Cecilia (eds.). La subversión del orden por la palabra. Tiempo, espacio e identidad en la crisis del mundo ibérico, siglos XVIII-XIX. Bilbao: Universidad del País Vasco-Euskal Herriko Universitatea, 2015. p.15-36.
El tiempo, ha dicho Franklin, es la tela de que está hecha la vida; y la vida misma es un bien fugaz y frágil que incesantemente se nos escapa.'

[Benjamin Franklin]

Oh tiempo! Dios solo conoce tu oscuro secreto. ${ }^{2}$

[José Eusebio Caro]

Introducción: temporalidades hispanoamericanas a principios del XIX La naturaleza especulativa de estas notas puede resultar extraña en boca de un historiador; tampocoson propias delfilósofo pues ellasinsisten en el carácter procesual del análisis y se elaboran a partir de una escena particular, la gran-colombiana durante la primera mitad del siglo XIX, un escenario cuya singularidad periférica parecería consignarlo a ser una nota al pie de página de la historia de la historia y de la historia de la filosofía. Tal vez sea posible, sin embargo, ver en esa ambigüedad algo del espíritu que propone el filósofo italiano Giuseppe Duso cuando insiste en la necesidad de cuestionar "las dos vías de análisis, aquella teórica (que se basa en la realidad sobre los conceptos históricamente determinados) yaquella sólo histórica (que implica en realidad conceptos de los que es necesario dar razón)" con que nos hemos acercado a la dimensión conceptual. ${ }^{3}$

En las próximas páginas argumentaré que el colapso del régimen monárquico y la institución del sistema republicano a principios del siglo XIX dieron cabida en la región neogranadina a una experiencia del tiempo que los mismos actores caracterizaron de precaria. En la segunda parte de este ensayo examinaré la respuesta intelectual a esa temporalidad precaria a partir de la obra de José Eusebio Caro (1817-53), filósofo, poeta, publicista y político neogranadino, uno de los fundadores históricos del partido conservador, observador astuto - y escéptico - de las "revoluciones políticas y morales" de las repúblicas hispanoamericana y recursoideológico de primerorden para el periodollamadola Regeneración colombiana (1886-1930).

República, tiempo precario

En un delicioso y divertido texto de 1799 que defiende con proposiciones silogísticas la tradición de comer ajiaco con pescado y buñuelos en la nochebuena bogotana, el autor sentenciaba que "... el que se aparta de la costumbre [engendra escándalos porque] manifiesta desconfianza de la autoridad suprema del legislador, de cuyo consentimiento le viene a la costumbrelafuerza deley..." ${ }^{4}$. Para suautor, eljurista neogranadinoFelipe VergarayCaicedo, lainnovación personal constituyeunacto arbitrarioque relativiza la potestad civil y militar, "da a entender que como se aparta de la ley consuetudinaria, se apartará también de la ley escrita, siempre que no se conforme a su capricho, en lo que presenta una insufrible sobervia y elección respecto del que govierna, a quien quiere enmendar la plana, improvándole su tolerancia" $(1993,49)$. La argumentación de Vergara y Caicedo evidencia la primacía, en las postrimerías del periodo colonial, de untiempoestrictamentereglado, el dela costumbre, ajustadosimultáneamente al calendario católico, al tiempo dinástico de la monarquía ibérica y a las exigencias de las tradiciones locales. Como ha sido reiterado en diversas ocasiones, en esa vivencia del tiempo la experiencia social y las expectativas colectivas tienden a corresponderse. ${ }^{5}$ 
6

SALAZAR, José María. Memoria descriptiva del país de Santa Fé de Bogotá, en que se impugnan varios errores de Mr. Leblond sobre el mismo objeto, leída en la Academia Real de las Ciencias de Paris.Semanario del Nuevo Reino de Granada, Bogotá, Imprenta Real de Santafé, n.27, julio 9 , 1809. Para un desarrollo de la emergencia de estos nuevos lenguajes y representaciones en el Virreinato de la Nueva Granada, ver SILVA, Renán. Los ilustrados de Nueva Granada 1760-1808. Genealogías de una comunidad interpretativa. Medellín: EAFIT-Banco de la República, 2002. En especial p.399-505.

7

La lectura de cartas, diarios, crónicas y viajeros fundamenta esta interpretación. Habría que aclarar que con excepción de aquellos sectores más reacios y cercanos al absolutismo fernandino, los actores del momento rehúyen el lenguaje apocalíptico. Para un ejemplo de la prosa eclesiástica condenatoria que, sin embargo, observa un tono relativamente sobrio, ver los memoriales dirigidos por el arzobispo de Caracas al rey: COLL Y PRAT, Narciso. Memoriales sobre la independencia de Venezuela. Caracas: Academia Nacional de la Historia, 1960. Para una visión de conjunto de las actitudes de la iglesia neogranadina, ver BIDEGAíN, Ana María. La expresióndecorrientesenlalglesianeogranadina ante el proceso de reformas borbónicas y la emancipación política (1750-1821). In: Historia del cristianismo en Colombia: corrientes y diversidad. Bogotá: Taurus, 2004. Para el caso venezolano, ver VIRTUOSO, Francisco José. La crisis de la catolicidad en los inicios republicanos de Venezuela (1810-1813). Caracas: Universidad Católica Andrés Bello, 2001. ALMARIO, Oscar. Continuidades y cambios en la percepción del tiempo, los acontecimientos y los imaginarios políticosdurantelaindependencianeogranadina. In: ORTEGA MARTÍNEZ, Francisco; CHICANGANA BAYONA, Yobenj. 200 años de independencias. Las culturas políticas y sus legados. Medellín: UniversidadNacionaldeColombia,2011.p.21-50.

8

LOZANO, Jorge Tadeo. Fragmentos de un diccionario genuino. El Anteojo de Larga Vista, Bogotá, En la Imprenta del Estado, n.2, 1814.

9

PROSPECTO.DiarioPolíticodeSantafédeBogotá. Bogotá, Imprenta Real, n.1, agosto 27, 1810, p.1.

10

PROSPECTO. Loc. Cit.

11

ROCAFUERTE, Vicente. Examen analítico de las constituciones formadas en Hispanoamérica. (1828). Reimpreso por Jaime Rodríguez en la sección de "Ensayos y Documentos" de la Revista de Historia de América, México, n.72, jul-dic., p.419-484, 1971.
Ese tiempo tradicional coexistía a finales del siglo XVIII, no sin dificultades, con un emergente horizonte de expectativas abierto a la acción transformativa y a la perfectibilidad social a través del patriotismo o de la acción útil. De hecho el mismo grupo de ilustrados al que pertenecía Vergara y Caicedo - y que luego asumirá la conducción de la Primera República-se encargó durante la última década del sigloXVIII de elaborar una nueva representación de la riqueza, el trabajo, la naturaleza y el saber que, como señalaría José María Salazar, allanarían “los obstáculos que retardannuestros progresosháciael suspiradotérminodeunacompletailustración" ${ }^{\prime \prime}$. A pesar de las inevitables fricciones entre estos dos horizontes deexpectativas,laexperienciacompartidadeltiempovirreinaldemostraba una probada consistencia y constancia.

Esa solidez se resquebraja durante el periodo de crisis y ruptura que empieza con la llegada de las noticias de la invasión napoleónica y las abdicaciones de Bayona en septiembre de 1808. Desde los primeros momentos de la crisis política los protagonistas americanos reclamaron estar viviendo un tiempo nuevo, azaroso y de cambio. Esta consciencia se pone en evidencia con la proliferación de llamadas a cabildos extraordinarios, las invocaciones a la revolución, las ubicuas alusiones a las novedades en todos los ámbitos de la vida social y política y la sensación generalizada deincertidumbrey crisis. El hecho se ofrecía simultáneamentefecundoen posibilidades perotambién inestable, próvidoen circunstancias inesperadas, azarosas y hasta amenazantes. ${ }^{7}$ Las palabras se revelaban incapaces de significar con claridad los alcances de las transformaciones políticas y conducentes ellas mismas a la confusión. Jorge Tadeo Lozano señaló en su Diccionario que"nada hay queempañetantolos lentes denuestro anteojo intelectual, comola acepción equívoca de las palabras; por desgracia es tal el trastorno que ahora se observa en esta materia, que corremos riesgo de experimentar la misma catastrofe que sufrieron los fabricantes de la Torre de Babel..." ${ }^{\prime \prime}$. La prensa - juntista y realista - acusaba a los rebeldes de dejarse seducir por el espíritu de innovación - al adoptar el lenguaje de la libertad y la soberanía del pueblo -y hasta los periódicos más firmemente comprometidos con la innovación política, como El Diario político de Bogotá, reconocía que los neogranadinos"fluctuamosen un Océanodeideas inconexas, sin experiencia, y casi sin principios..." ${ }^{\prime 9}$. Ese reconocimiento vertiginoso de la ineficacia de la experiencia acumulada co-existía en los periódicos con la voluntad de convertirseen superficies privilegiadas para "que nuestros Franklines y nuestros Washingtones derramen luxes y fixen nuestra inconstancia y nuestra incertidumbre"10.

Por un breve lapso de tiempo (1821-24) pareció que el orden republicano lograría consolidarse y colmar las expectativas generalizadas. La ola de entusiasmo generada por la racha de victorias bolivarianas a partir de 1819 y la rápida edificación de una institucionalidad republicana la República de Colombia - fundamentaron la sensación de un destino grandioso. El guayaquileño Vicente Rocafuerte expresó ese optimismo al señalar en su reseña del constitucionalismo americano que las nuevas repúblicas privilegiaban de manera consistente los preceptos republicanos conducentes a la libertad, en contraste con las disposiciones típicas de las naciones europeas, conducentes al despotismo. ${ }^{11}$ Sin embargo, el incumplimientocolombianodelasobligacionesfinancierasenLondresyla progresiva polarización políticay social en la escena local evidenció que el tiempopromisorioera efímeroeilusorio.Para 1826 el profundopesimismo 
Fabio Wasserman ha descrito un proceso similar en el Río de la Plata. Para Wasserman la revolución rioplatense dio lugar a una nueva experiencia de tiempo orientada hacia el futuro y signada por la ruptura con el pasado, la aceleración y la temporalización de la política que, sin embargo y contra lo que cabría esperar, no forjó un nuevo concepto de tiempo. Trabajo leído en el CONGRESO INTERNACIONAL "EXPERIÊNCIAS DE TEMPO NOS SÉCULOS XVIII E XIX", del 23 al 25 de abril del 2014, Universidad de São Paulo, São Paulo.

13

PALTI, Elías. El tiempo de la política. Buenos Aires: Siglo XXI, 2007. p.51-56.

CARRERA DAMAS, Germán. República monárquicaomonarquíarepublicana.In:Historia de América Andina. Tomo 4: Crisis del Régimen colonial e independencia. Quito: Universidad Andina Simón Bolívar, 2003. p.359.

15

Existe, sin duda, una lectura historiográfica reciente que cuestiona la inevitabilidad y naturalidad de tal transición. Ver, por ejemplo, AGUILAR, José Antonio; ROJAS, Rafael (eds.). El republicanismo en Hispanoamérica. Ensayos de historia intelectual y política. México: CIDE-FCE, 2002; CASTILLO ROJAS, Vasco. La creación de la República: la filosofía pública en Chile, 18101830. Santiago de Chile: Lom Ediciones, 2009; ENTín, Gabriel. De la república desincorporada a larepúblicarepresentada.Ellenguajerepublicano durante la revolución del Río de la Plata. In: MUÑOZ, Marisa; VERMEREN, Patrice (eds.).

Repensando el siglo XIX desde América Latina y Francia Homenaje al filosófo Arturo A. Roig. Buenos Aires: Colihue, 2009; ROJAS, Rafael. Las repúblicas de aire. Utopía y desencanto en la revolución de Hispanoamérica. México: Taurus, 2009; y, el más reciente, AGUILAR RIVERA, José Antonio.Ausentes deluniverso.Reflexionessobre el pensamiento politico hispanoamericano en la era de la costruccion nacional, 1821-1850. México D.F.: FCE, 2012. había embargado a los más decididos republicanos - incluidos Bolívar y Rocafuerte - quienes a su vez se vieron obligados a modificar sus programas políticos.

El exagerado pesimismo y el intenso optimismo son dos caras recurrentes a los largo del siglo XIX de la misma moneda: expresiones coyunturales posibles sólo porque existe otra característica aún más definitoria dela conciencia histórica y la experiencia colectiva de este tiempo de transición. Esa característica - que podríamos definir de antemano como una textura precaria de la experiencia colectiva del tiempo histórico - resulta a la vez obvia y muy difícil de aprehender. ${ }^{12}$ Los términos más recurrentes por la historiografía contemporánea para describir esta textura temporal del sattelzeit local - es decir, voces como modernidad y tradición - resultan descriptivamente pobresyanalíticamenteinsatisfactorios, además de acabar implicadas en un entramado teleológico. ${ }^{13}$ Este texto se desmarca de ese lenguaje e identifica - de manera muy sucinta - el fundamento de esa temporalidad precaria vinculándola a la crisis generalizada propiciada por el colapso de la soberanía real y la adopción de la forma republicana con el objetivo de enriquecer nuestra paleta descriptiva de las temporalidades experimentadas durante el periodo republicano a través de la identificación del lenguaje de los contemporáneos.

No exageramos si señalamos que un factor importante para la precariedad delos nuevos tiempos tienequevercon la desaparicióngradual de antiguas lealtades tras-atlánticas y la erosión de los principios políticos que fundaban la soberanía en la figura del Monarca. La re-constitución de una nueva comunidad política - por fuera de la monarquía - y la búsquedadefundamentosnuevos delegitimidadanimanunageneración de americanos que se sienten embargados por el abanico de posibilidades. El conjunto de transformaciones violentas e intensas dislocó-como lo ha señalado el historiador venezolano Germán Carrera Damas - la estructura de poder interno de la región de tal manera que buena parte de la historia político intelectual del sigloXIX se constituye en un intento por especificar la naturaleza de tal dislocamiento y abordarla a través de un granado"....semillero de cuestiones jurídicas, políticas y socio-políticas - y de sus expresiones ideológicas"14.

En ese sentido, la temprana y vigorosa adopción de un vocabulario republicano y su posterior desarrollo institucional en el contexto de los nuevosestadosindependientesamericanosconstituyeunarespuestacreativa, contundenteyenigmática a la precariedad queemerge con la crisis de losfundamentosquelegitimabany hacían plausibleydeseableel régimen monárquico y la eventual disolución de la comunidad hispánica transatlántica. Ahora bien, buena parte de los estudios sobre la emergencia del republicanismo en la América hispánica han dado porsentadola inevitabilidad de la transición y lo han asociado - sino confundido - con el liberalismo y nacionalismo. Sólo hasta muy recientemente la historia política ha comenzadoa exploraresterepublicanismocomounlenguaje políticoque requiere de mayor dilucidación. ${ }^{15}$

Sinembargo, quizásea hora depensarenel republicanismoamericanocomofundamentalmentealgomásqueunaformadegobierno(opuesta a la aristocracia o a la monarquía) o un conjunto de ideas (separación de poderes, constitucionalismo, etc.) y abordarlo, como sugiere John Pocock, como un tipo de historicismo que surge de la necesidad de innovar conceptualmentepararespondera"losefectosqueproducía en loshombresla 
POCOCK, John Greville Agard. El momento maquiavélico.Elpensamientopolíticoflorentinoy latradiciónrepublicanaatlántica.Madrid:Tecnos, 2002. p.518.

17

Ibidem, p.138.

18

Ibidem, p.133.

19

Con frecuencia la experiencia republicana se convierte en la sensación de haber perdido el "punto fijo" de la sociedad. No extraña pues que la acción política se entienda como el intento por dotarla de un punto fijo. En 1826 Simón Bolívar propone la figura de un presidente vitalicio para la Constitución de la recién creada República de Bolivia y señala que: "El Presidente de la República viene a ser en nuestra Constitución, como el sol que, firme en su centro, da vida al Universo. Esta suprema autoridad debe ser perpetua;porqueen lossistemassinjerarquíasse necesitamásqueen otros un puntofijoalrededor del cual giren los magistrados y los ciudadanos: los hombres y las cosas. Dadme un punto fijo, decía un antiguo, y moveré el mundo. Para Bolivia, este punto es el Presidente vitalicio. En él estriba todo nuestro orden." BOLIVAR, Simón. Proyecto de Constitución para la República de Bolivia y Discurso del Libertador. Lima: en la oficina del ciudadano AlejandroValdés, 1826.p.7.

20

Esta reflexión de Pocock no está muy lejana de la anotación que ha hecho Pierre Rosanvallon sobre las relaciones de la democracia con el tiempo, como una variable activa y constructiva del nuevo régimen político. Ver ROSANVALLON, Pierre. Por una historia conceptual de lo político. Buenos Aires: FCE, 2003. p.51.

21

POCOCK, John Greville Agard.Op.Cit., p.268-269.

22

REAL ACADEMIA ESPAÑOLA. Diccionario de

la Lengua Castellana compuesto por la Real Academia Española, Reducido a un tomo para su más fácil uso. Madrid:Imp. delaViuda de Joaquín Ibarra, 1791.

23

BOLÍVAR,Simón.OracióninauguraldelCongreso deAngostura.In:DoctrinadelLibertador.Caracas: Biblioteca Ayacucho, 2009. p.124. LASO, Benito. Exposiciónque hace el Diputadoal Congreso por laprovinciadePuno.Lima:ImprentaRepublicana Administrada, 1826. p.13.

24

LASO, Benito. Op.Cit., p.14. Un buen catálogo de males se puede encontrar en COLOMBIA en 1828 o lo que debería ser Colombia en 1828. Caracas: Devisme Hermanos, 1827. p.11-19. pérdida de la estructura de su costumbre"16. En otras palabras, el lenguaje político de la república aparece como un historicismo que responde a las dificultades evidenciadas por las formas políticas vigentes para anclar la comunidad en los anheladosfundamentos trascendentales. La propuesta republicana, de ese modo, "significaba ... romper la continuidad eterna del universo jerárquico en una infinidad de momentos particulares"17. Es por eso que "Una comunidad construida en la costumbre en un rincón del orden eterno no es una república de ciudadanos"18.

La república adviene, por lo tanto, como signo y respuesta a una experienciacomunaldeltiempoquehaperdidosupuntofijo. ${ }^{19}$ Peroeltipo de respuestaqueellaconstituyegeneraasuvezgranansiedad.Laexperiencia republicana, señalaPocock, noconstituyeunaentregadócilaesatemporalidaddesprovistadefinalidadtrascendente.Alcontrario,elrepublicanismo poneenmarchaunsegundomomentoquerequiereunaconcepciónactiva del hombre para enfrentar, a través de la prudencia, fortuna o virtud, la precariedad del tiempo-experiencia. ${ }^{20}$

Esporeso queel sistema republicano exige un pueblovirtuoso, industrioso y capaz, a través de su espíritu patriota y del uso de sus facultades deliberativas, degenerarriquezay dellegaraobjetivoscomunes.Comobien señala Pocock la república ha estado asociada"a una estructura de virtud... en la que la disposición de cada ciudadano a anteponer el bien común al suyo propio era la condición previa de todo lo demás"21 ; la misma existencia de la república - "el gobierno del público", según el Diccionario de la Real Academia ${ }^{22}$ - depende del compromiso de los ciudadanos de preservarla a través de su virtuosismo, es decir de su capacidad de resistir los avatares de la fortuna. Ese virtuosismo cívico o vivere civile del pueblo permite navegar los peligros dela existencia política. El pueblo seconvierteen sujetoy objeto de la política, lo que explica que a principios del siglo XIX la adopción del modelo republicano obliga a las elites a elaborar conceptualmente la figura delpueblo,tantocomofundamentodelegitimidad,comoagenciadeemancipación política y como categoría de administración y control.

Sinembargo, para los mismos americanos republicanos entusiastas, el pueblo no era virtuoso; vivía bajo el "triple yugo de la ignorancia, de la tiranía y del vicio"; no poseía, según la prosa de la época, las "Nobles pasiones, que son el resorte de las virtudes cívicas" ${ }^{\prime 23}$. El diagnóstico era repetido y coincidía en que varios eran los factores que habían contribuidoaldecididoembrutecimientodelpueblo:elrégimencolonialespañol que lo envileció al cerrarle las puertas a la industria y acostumbrarlo a sus cadenas; la falta de oportunidades y la inexperiencia en cuestiones políticas; la escasez de la población diseminada sobre un amplio territorio; la proliferación de clases diversas, la heterogeneidad de intereses y el origen salvaje de buena parte de su población. "En consecuencia”, señalaba un cercano colaborador de Bolívar, "no se conoce en nuestras jentes el espíritu nacional, que es el fomento poderoso del amor patrio y el nombre de [Colombiano] apenas tiene en el vulgo un vagoéindiferente significado"24.Paradójicamente,entonces,laconsolidaciónconceptualdel término república coincide con dos fenómenos contrarios: 1) la incipiente pero efectiva ideologización y democratización del lenguaje republicano entre amplios sectores sociales y su apropiación militante en el contexto de la guerra contra España; y 2) la percepción - por parte de buena parte de la elite-que el pueblo es el agente social por excelencia que amenaza permanentemente con disolver el orden social. 
25

El cartagenero Juan García del Rio planteo en su libro Meditaciones colombianas (1829) la necesidad de configurar una monarquía constitucionalenlaRepública deColombiacomo el diseño institucional apropiado para defender la libertad, mantener la unidad y contener la anarquía popular. Por su parte, Simón Bolívar fue el primeroen proponerunapresidenciavitaliciay un cuarto poder moral para velar por la conducta pública en el Discurso de Angostura (1819) y el Mensaje al Congreso Constituyente de Bolivia (1826)

26

VerORTEGA MARTÍNEZ, Francisco A. AndWhere Are the People?: Genealogies of the pueblo During the Late Eighteenth and Early Nineteenth Century. In: Latin American Popular Culture: Politics, Media, Affect. Rochester, NY: Tamesis Books, 2013. p.45-70.
Para un desarrollo de esta crítica, ver CHAKRABARTY, Dipesh. Provincializing Europe. Postcolonial Thought and Historical Difference. Princeton, NJ: Princeton University Press, 2000. 28

ROCAFUERTE,Vicente.Ensayopolítico.Elsistema colombiano, popular,electivo,yrepresentativoes elquemásconvientealaAméricaindependiente. Nueva York: Imprenta de A. Paul, 1823. p.6; p.11.
Esa percepción significó tempranamente que para estas elites gobernarsignificabafundamentalmentepacificarsociedadesanárquicas. Esto podría llevarse a cabo a través de un retorno de la monarquía, de la institución de una república aristocrática, de una presidencia vitalicia o a través de la elaboración de un cuarto poder a cargo de velar por una conducta pública virtuosa. ${ }^{25}$ Pero ninguno de esos proyectos logró imponerse de manera contundente en la Nueva Granada. Y esto, en buena medida, porque ninguno de los grupos en conflicto - ni los diversos grupos de las elites, ni las regiones, ni los grupos subalternos - tuvieron la capacidad ni la posibilidad de movilizar los recursos necesarios para realizar sus expectativas sociales y someter las de los grupos rivales. Ningún grupo social pudo ofrecer de manera definitiva un pueblo - darle cuerpo a ese pueblo a su imagen y semejanza - en el que la nueva temporalidad republicana pudiera anclarse. ${ }^{26}$ En cambio, a lo largo del siglo - por lo menos hasta la llamada Regeneración en 1886 - se impuso la coexistencia exacerbada de diversas e incluso antagónicas expectativas sociales, lo cual agitó la contienda política y la llenó de contenidos socialmente inestables.

De ese modo, la construcción de las nuevas repúblicas americanas se presentabacomounanegociaciónagónicaentreelvértigodeloqueirremediablementedesaparecía-losfundamentosdeunasoberaníatrascendente - y las expectativas de lo que aparecía como posible - la co-producción de una nueva legitimidad basada en la virtud cívica del pueblo. En términos koselleckianosla precariedaderael resultado de 1) unaexpansiónacelerada delhorizontedeexpectativas-consuapropiacióngeneralizadapordiversos sectores sociales; 2 ) una reducción de la capacidad de la experienciaacumulada-o, como diría Pocock, de la estructura de costumbre-para sortear las dificultades;3) unaevidenteinsuficienciadelosrecursossocio-culturalese institucionales disponiblespararesponderdemaneraefectivaalosnuevos retos políticos;y,finalmente,4) la ausencia de un sujeto hegemónicocapaz de imponer su voluntad política sobre el cuerpo social. El largo siglo XIX neogranadino es un intento agónico por recuperar un punto de equilibrio social y un lugar protagónico para las elites que se consideraban llamadas para asumir la conducción de la nueva república.

Si bien Koselleck plantea la historicidad del tiempo en un plano novedoso, lostérminosqueemergen paracaracterizarla (modernidad-tradición) resultan reductivos. Sin duda, el desajusteentre experienciasy expectativas es precisamente la tensión que, de acuerdo a Koselleck, da pie a la historicidad vigentepero, comoveremosmás adelante, designaresetiempomoderno resulta tan insatisfactorio como llamar tradicional a la experiencia de tiempo que desplaza. Aún más, para el caso de Hispanoamérica, el binomio nos remite ineludiblemente al laberinto de una modernidad que se antoja siempre problemática y con apellido - a saber, periférica, diferida, derivativa, impostada, etc. - y su corolario inevitable: la modernización, es decir, la consciencia historiográfica de que lo que pasaba en Europa es lo que debía pasaren la América hispánica. ${ }^{27}$ Pero, por el contrario, el periodoen cuestión da muestras suficientes de los esfuerzos generalizados por imaginar aquel sistema que"convieneá nuestroclima, á nuestra escasa poblacion,á nuestra riqueza, á nuestra índole, y á nuestro estado de civilizacion", siempre en la convicción "de que esta nueva parte del globo, exige un nuevo sistema de legislacion, muy diferente de todo lo que se há conocido hasta aquí"28.

No dejemos de advertirque los contemporáneos perciben otros signosdeaceleracióndeltiempo,signosqueprovienendelordeneconómicoe 
29

AROSEMENA, Mariano. Apuntamientos Históricos 1801-1840.[1868].Panama:Autoridad del Canal de Panamá, 1999. p.133.

30 Ibidem, p.5
31

GALAVIS, José María. Preceptos de moral. In: El hombre honrado y laborioso. Bogotá: Imprenta de J. M. Cuallar ,1842. p.7. Ver también CALLEJA, Tomás. Hacia una nueva gestión del tiempo. In: La experiencia social del tiempo. Pamplona: Ediciones Universidad de Navarra, 2006. p.203212.Lanuevagestión del tiempoparececoincidir con las revoluciones políticas. Desde muy temprano se publican ensayos, como el de Marc Antoine Jullien, "Sobre el empleo del tiempo". El extracto apareció en el primer volumen de El Repertorio Americano (1827) y proviene de su libro Essai sur l'emploi du temps 1810.

32

ACEVEDO GÓMEZ, Josefa. Tratado sobre economía doméstica parael uso delasmadres de familia i de las amas decasa. Bogotá:Imprenta de José Acualla, 1848. p.5-6.

33

GALAVIS, José María. Op. Cit., p.7. inclusotecnológicoyque parecerían serlos verdaderosfundamentos dela aparición de una temporalidad nueva. En primera instancia aparece entre varios publicistas y economistas del periodo una preocupación por la correcta administración del tiempo en virtud de su potencia productiva. Esta preocupación pasa por la censura de lo que el patricio panameño Mariano Arosemenallamó"loshábitosenvejecidosylaspreocupacionescoloniales" en favor del "verdadero progreso para un país recién salido de la esclavitud". ${ }^{29}$ La colonial estaba hecha de"hábitos engendrados ..., como la lidia de toros, las carreras de caballos, las peleas de gallos, y el ocio perpetuo. Para esos pasatiempos y holganza se tenían más de cien días festivos al año"lo cual había conducido a los habitantes de la colonia al "abatimiento y degradación" ${ }^{\prime 30}$. El afán de estos críticos por inculcar una nueva ética del trabajo, sujeta a ritmos industriales, al cálculo financiero, el disciplinamiento obrero, coincide con múltiples esfuerzos a lo largo y ancho del territorioneogranadino.JoséMaríaGalavisadmonizaenelHombrehonradoy laborioso (1842) que

\section{Antes de dormir dirije \\ Una mirada severo \\ Sobre las horas del dia \\ Para saber el empléo \\ Que le hayas dado... ${ }^{31}$}

El Tratado sobre economía doméstica (1848), de Josefa Acevedo de Gómez, extiende esta reflexión a la mujer de capas medias:

\begin{abstract}
No podemos adivinar ciertamente cuanto dinero, cuantos bienes de todas clases, podrá concedernos la Providencia. Empero, sí sabemos que la mas larga vida no alcanza ordinariamente a la duración de un siglo. Deduciendo de ella la época de la infancia ..., los días empleados en la primera educación ..., lo que nos quitan de la existencia activa el sueño y las enfermedades, ¿que nos resta? Un breve espacio, un instanteimperceptible, sihemos demedirlecomparándoleconlainmensidad de nuestros deseos, la estension de nuestrasesperanzas, y la viveza ardiente de nuestra imaginacion.Estos....cuarentaocincuentaañosdeuna precariaéinciertaduracion, son de la mayor importancia, son nuestro tesoro, puesto que de ellos se compone nuestra existencia. ¿l qué uso hacemos de ellos? Los prodigamos, los perdemos lentamenteporhoras, porminutos, porsegundos, dejandoescapar, sin provechode nadie, el progreso inestimable de la vida.... ${ }^{32}$
\end{abstract}

Deestemodo"... la mujer laboriosa [aparece] siempre ocupada, ó en la costura y bordado, ó en el manejo doméstico ... [y es, de ese modo,] la delicia de su familia y el honor de su sexo"33.

Estas crítica y admoniciones de la temporalidad tradicional se dirigían contra lo que se consideran costumbres irracionales y arraigadas que impedían el advenimiento del progreso y la llegada de una verdadera experiencia moderna. Son, en otras palabras, una racionalidad económica deseada pero que hallaba expresión justo en la ausencia de su realización social.Ynoera para menos.Lasociedadyeconomía neogranadina notenía grandes industrias y sólo se había vinculado precaria y recientemente al mercadoglobala partir de sus sectores primarios de explotación agrícolael cacao, el tabaco, la quina, el café. Como ilustran los ejemplos anteriores, las expectativas colectivas presentes en la Nueva Granada no derivan de la apropiación efectiva de los beneficios o padecimientos de las actividades yprocesostecno-industriales, sinoqueconstituyen proyeccionesimagina- 
34

Por ideológico no me refiero al tipo de mediaciones que velan a la consciencia la naturaleza verdadera de las relaciones de dominio. Me refiero en cambio a la dinámica que-como dice Furet-“podría llamarse política, ideológica o cultural, para decir que su múltiple poder demovilización deloshombresydeacción sobre las cosas pasa por un reforzamiento del sentido". FURET, François. Pensar la Revolución Francesa. Madrid: Ediciones Petrel, 1980. p.36.

35

Los novatores a su vezacusaban a sus contrarios de despóticos. Bolívar había señalado que la tiranía y el despotismo son los dos grandes "monstruos enemigos" que amenazaban las repúblicas hispanoamericanas. BOLÍVAR, Simón. Proyecto de Constitución para la República de Bolivia y discurso del Libertador. Lima: Imprenta Republicana, 1826. p.4.

36

AROSEMENA, Justo. Apuntamientos para la introducciónálascienciasmoralesypolíticas, por un jóven americano. Nueva York: J. de la Granja, 1840. p.63. tivas sobre el cuerpo social por medio de las cuales se conciben las transformaciones necesarias para alcanzar la anhelada revolución industrial. La ausencia de una economía consolidada podía ser interpretada-y sin duda lo fue con frecuencia - como un factor que contribuía a la falta de cohesión y fragilidad de las sociedades americanas; sin embargo, estos signos de deseo no constituyeron el fundamento de la sensación de precariedad que abunda en el periodo.

Conestoselementosinicialesquiero aventurarcinco hipótesis sobre la naturaleza de esa nueva temporalidad republicana. En primer lugar, es importante recalcar que el fundamento social de las nuevas temporalidades en la Nueva Granada era ideológico (y que no sería de otra índole hasta mucho después). ${ }^{34}$ Eso no quiere decir que fuera falso o derivativo. Pero sí explica la manifestación propiamente política y la dificultad que los teóricos sociales han tenido para dar cuenta de su especificidad. En segundo lugar,latemporalidadresultaba precaria porque-entérminoskoselleckianos-la distancia entre las experiencias disponibles y losfuturos plausibles se agrandaba mientras que la percepción generalizada de los recursos materiales y socio-culturales para satisfacer esas nuevas aspiraciones era la de la una dramática insuficiencia. Es decir, son expectativas que estaban condenadas a generar frustración, incertidumbre, e inestabilidad.

En tercer lugar, habría que señalar que no existieron grupos sociales consolidados, con la capacidad efectiva de imponer su voluntad sobre el cuerpo social.Lo que existió, en cambio, fue una pluralidad de actorescontenciosos, cada uno con la intención de imponer su historicidad particular. Esa carencia de un liderazgo político por parte de la elite exacerbó la condición de fragilidad social del periodo y la urgencia de darle una solución política que estuviera a la vez por fuera de la contienda pública, es decir, de la política. En cuarto lugar, habría también que advertir que en tanto se carece de los medios y de la voluntad para imponer un régimen de historicidad, esa misma temporalidad - o régimen de historicidad republicana - se convierte en objeto de disputa a través de conceptos como virtud, moral, civilización y, posteriormente, modernización, términos todos que van a querer darle sustancia - es decir, en este caso, dotar de temporalidad consistente - al concepto "pueblo".

Finalmente, esa consciencia ideológica - es decir, la conciencia de la primacía de los factores retóricos sobre las"causas reales"o, para decirlo de otra manera, de la disputa política - acompañara a los actores americanos a lo largo del siglo XIX y los llevará, con frecuencia, a acusar a los novatores de introducir la anarquía. ${ }^{35}$ Las palabras de un liberal, como el panameño Justo Arosemena, vinculado a la elite comercial del istmo (mucho más cercana a Kingston que a Bogotá) resultan ilustrativas en este sentido. Arosemena reconocerá, con alarma, la fuerza de las ideas en las revoluciones:

Quizálas revolucionesqueenestosúltimostiemposhanmudadoelaspecto político devarias naciones, sometiéndolas á un réjimen mas liberal queel innecesariamente (restrinjidoáqueestaban sujetas), se deben en gran parteálas nociones de libertad contenidas en el libro de Rousseau que trata del sistema que hemos censurado... ${ }^{36}$

Estos cinco puntos nos deben llevar a reconocer que el binomio modernidad-tradición - con que mucha de la historiografía política continua describiendo la conflictividad propia del siglo - no sólo resulta inadecuada para acercarse al tiempo precario que anima el sattelzeit hispanoamericano, sinoqueesunequívocoteóricoqueinscribeelcomplejo 
Ver GALVIS SALAZAR, Fernando. José Eusebio Caro. Bogotá: Imprenta Nacional, 1955. Ver también ALJURE CHALELA, Simón. José Eusebio Caro: bibliografía, Issue 1. Charlottesville, Virginia:Bibliographical Society ofTheUniversity of Virginia, 1967; OSPINA ORTIZ, Jaime. José Eusebio Caro. Guión de una estirpe. Bogotá: Publicaciones Técnicas, 1957.

38

CARO, José Eusebio. Sobre el lujo. In: El hombre honrado y laborioso. Bogotá: Imprenta de J. M. Cuallar, 1842. p.32.

39

Idem. Observaciones sobre la distancia de tiempo en las sensaciones y del influjo de esta circunstancia sobre su valor o su peso si se quiere.In:ALJURECHALELA, Simón (ed.). Escritos filosóficos. Bogotá: Ministerio de Educación Nacional, 1954. p.261.

40

Idem. Capítulo I:“El hombre en movimiento”. In: Mecánicasocialoteoríadelmovimientohumano, considerado en su naturaleza, en sus efectos yen sus causas. Bogotá: Instituto Caroy Cuervo, 2002. p.124.

41

Ibidem, p.133. Al respecto afirma Caro, el movimiento es lo más cierto: "Algo se mueve siempre en el individuo. Algo se mueve siempre en la sociedad. Esto lo hemos visto con nuestros ojos, lo hemos escuchado con nuestros oídos, lo hemospalpadoconnuestrasmanos.Nopodemos asegurarnos mejor de un hecho, no podemos llevar más lejos la certidumbre en la prueba de la observación". Ibidem, p.128. Es importante clarificar que Caro no termina nunca el manuscrito y éste no se publica durante su vida. 42

Ibidem, p.124.

43

Ibidem, p.133.

Ibidem, p.139. proceso de construcción institucional americano en un marco teleológico reduccionista.

Sociedad en movimiento, tiempo cohesionador y moral republicana Ahorabien, ¿cómorespondenlosactorescontemporáneosaltiempoprecariodelarepública?¿Quéfigurasretóricas, quéelaboracionesconceptuales y quéargumentos presentan para enfrentarse a la fragilidad de su presente? En lo que me queda de espacio no puedo abordar satisfactoriamente esta pregunta, pero quisiera simplemente identificar algunos elementos importantes para responderla a través de la obra de José Eusebio Caro. ${ }^{37}$ Mi decisión de tomar una figura conservadora - y del calibre de Caro - es un intento por evitar las respuestas fáciles - predecibles - que podrían producirse al examinar la obra de un ideólogo liberal. En efecto, la trayectoria intelectual de Caro puede entenderse como respuesta a este tiempo precarioy desafíalas formas usuales con queentendemos la conflictividad propia del periodo republicano hispanoamericano.

Caro participa en las máximas modernizantes del tiempo calculado. En varios panfletos ataca la ostentación de las elites coloniales y aboga por una nueva ética de la economía política. "No son los lujos [propios de una sociedad colonialy estamental] los que hacen prosperar una sociedad queflorece, sinoloshombreseconómicos, moderadosyprudentes" ${ }^{\prime \prime 38}$.Más importante, en tanto hombre público - congresista, ministro de Hacienda y reformador del sistema contable de la Nueva Granada - Caro procura "calcular rigurosamente [el tiempo] por signos algebraicos"39. para aplicarlotanto en las funciones administrativas delas nuevas repúblicascomo en las necesidades morales de sus ciudadanos. Él mismo entiende su obra como una respuesta a los retos presentes en regiones habitadas por "Un inmensomontóndehombresenmovimientoincesante ${ }^{\prime \prime 4}$.Esemovimiento - una sensación común a las comunidades euro-atlánticas - ocurreen una sociedad con gran necesidad de produciry sentir la cohesión yorden en un cuerpo social siempre amenazado por la inminente disgregación.

Contrario a lo que esperaríamos encontrar en un conservador hispanoamericano, Caro es un pensador del movimiento social: el"movimiento es vida", afirma en su manuscrito de 1836 Mecánica social o teoría del movimiento humanoconsiderado en su naturaleza, en sus efectosyen sus causas. ${ }^{41}$ En el ensayo se propone elaborar una ciencia por medio del cual se clasifica y calcula el movimiento humano:

Atravesemos de polo a polo una ciudad cualquiera, a Bogotá, por ejemplo: atravesémosla desde el Convento de San Diego hasta la nueva fábrica de loza....En las calles más retiradas, en los arrabales más solitarios, difícil es que se corra un día, difícil es que se corra una hora, media hora, un cuarto hora, sin que aparezca una figura móvil que los anime, un hombre que les de vida. ${ }^{42}$

El principio fundante de la existencia social es su carácter dinámico: "el caso de absoluta inmovilidad es imposible: es imposible para el individuo, es imposible para la sociedad.... Sociedad inmóvil, sociedad nula.... Sociedad inmóvil no es sociedad, es cementerio" ${ }^{\prime \prime 3}$.

Identifiquemos cuatro características del modo en que Caro aborda ese movimiento social. En primer lugar, si bien el movimiento caracteriza todo individuo y a toda sociedad, la acción "no es movimiento indeterminado [o ideal], es un movimiento específico", ${ }^{44}$ es decir, cada sociedad tiene un "movimiento variable, concreto, individual", histórico. "En fin mover- 
Tomado de JARAMILLO URIBE, Jaime. EI pensamiento colombiano en el siglo XIX. Obras completas de Jaime Jaramillo Uribe. MéxicoBogotá: Alfaomega-CESO, 2001. p.155.

47

CARO, José Eusebio Caro. Capítulo I: "El hombre en movimiento". Op. Cit., p.155.

\section{8}

Son entonces, las obras humanas: templos, monumentos, libros, caminos, ciudades etc., los vestigios de la infatigable acción del hombre, entendido a la vez como "el vestigio de la acción de otro hombre". Ibidem, p.134.

49

Ibidem, p.134-135.

se, es moverse de un designado modo" $(2002,139)$. Es por este carácter histórico del movimiento queéste"establece ... las principales diferencias entre hombrey hombre" $(2002,132)$. Cada individuo, sociedad, periodo se distinguen por"la especie particular de movimiento que con ciertas cosas y sobre ciertos objetos producen habitualmente" $(2002,132)$. En segundo lugar, la heterogeneidad es pues constitutiva del movimiento social:

\begin{abstract}
Hombres de todas especies, de todos sexos, de todas edades, de todas condiciones; blancos, indios, negros, mozos, viejos, niños, mujeres, artesanos, mendigos, soldados, frailes, mercaderes; hombres de todas caras, de todos vestidos, de todas estaturas; hombres a pie, hombres a caballo; en tropa o separados, atrás o adelante, siguiéndose o encontrándose; todos estos hombres, todo este furioso remolino de hombres, obstruyen las salidas y las entradas, inundan puertas, almacenes y pavimentos; y arrojan de su seno una especie de bramido ronco, semejante al que sale de entre los gruesos borbollones que se atropellan y se suceden en una caldera hirviendo: todos se mueven. ${ }^{45}$
\end{abstract}

La heterogeneidad es un elemento esencial de la sociedad. "Sin ella la simple pluralidad degeneraría en rivalidad. Entre iguales apenas hay sociedadposible.Lavariedadeslaqueproduceladependenciamutua, que es la base del progreso y de la estabilidad de los sexos, oficios, servicios y ocupaciones, pues esta es la única variedad armónica:todas las demás son antagonistas" ${ }^{\prime \prime 6}$.Ladiversidad, necesariamenteconstitutiva del cuerposocial, es el resultado del movimiento:"... en la ciencia social como en electricidad es cierto el teorema: las fuerzas de la misma especie se rechazan: las de distinta especie se atraen"47.

En tercer lugar, el movimiento conlleva múltiples temporalidades. No sólo el movimiento está en la acción presente. El movimiento presente significa la presencia activa de temporalidades pasadas, en la forma de "vestigio de la acción pasada, y junto, el anuncio de la acción futura" $(2002,134)$. Todo tiempo existe henchido de diversos futuros:"El hombre es el vestigio de otro hombre, así como todo presente "Ileva encerrado en su seno el semillero oculto de nuevos hombres y de nuevas sociedades" $(2002,134){ }^{48}$

Finalmente, para Caro el movimiento no era un fenómeno reciente. De hecho, no hay circunstancia más permanente en el ser humano que el cambio:

\begin{abstract}
... el hombre, como hombre, supone el movimiento, mientras el hombre haya sido hombre lo habrá supuesto necesariamente, mientras el hombre sea hombre lo supondrá necesariamente también.... Luego el movimiento humano existió en lo pasado y existirá en lo futuro. ... ¿Qué es, pues, un hombre, en fin? Una acción continúa. ... Un movimiento inmenso. ${ }^{49}$
\end{abstract}

Sin embargo, en el presente había ocurrido una especie de aceleración que le daba al movimiento social un carácter diferente. ¿Y cuáles eran los factores que habían causado ese cambio? Caro identifica tres factores: el impacto de las nuevas tecnologías, el incremento de la productividad y la globalidad. Todos tres modifican el proceso de constitución de la sociedad actual de tal manera que explican la especificidad de la aceleración temporal. Ellos constituyen un salto que - como dice Caro - introducen la posibilidad de cambio.

Caroseñala, en primerlugar, quelas sociedades recientes han idoadquiriendo"podereshumanos...extrínsicamentepormediodelosinventos 
CARO, José Eusebio. Observaciones sobre la distancia de tiempo..., Op. Cit., p.186.

51 Idem.Capítulol:"El hombreen movimiento".Op. Cit., p.187.

52

Ibidem, p.186-187; p.188.

53

CARO, José Eusebio. La bendición nupcial. Op Cit., p.201.

54

CARO, José Eusebio. Loc. Cit.

55

Ibidem, p.239-240. Más adelante: El texto solo contiene "una serie hilada de observaciones, observaciones hechas de la manera más imparcial, y entre las cuales ni una sola máxima se encontrará relativa a las acciones que deben o no deben ejecutarse" (240). En esto, como en otras cosas, Caro sigue a Comte:"Tampoco debe considerarse la moral como una entidad que ofrece recompensa, que amenaza con castigos; esoesconfundirlaconlareprobación,aprobación y opinión popular, con la ley, y con la religión divina. La moral, pues, no puede ser más que una ciencia: una ciencia de observación como todas las otras, que ni obliga, ni exonera, que ni promete, ni amenaza". Ibidem, p.237. De Comte, Caro sigue Plan de trabajos científicos para reorganizar la sociedad (1822) y su monumental Curso de filosofía positiva (6 vols, 1830-1842).

56

CARO, José Eusebio. Capítulo I: “El hombre en movimiento". Op. Cit., p.236-237.

57

Ver, principalmente, BENTHAM, Jeremy. An Introduction to the Principles of Morals and Legislation. Impreso por primera vez en 1780 y re-impreso con correcciones en 1823. En 1821 Toribio Núñez traduce y publica la obra en Salamanca bajo el título de Principios de la ciencia socialó de las ciencias morales y políticas. Salamanca: Imprenta Nueva, por don Bernardo Martin, 1821. Para el momento que Caro trabaja en la Mecánica social, el salamantino Toribio Núñez publica una Ciencia social según los principios de Bentham (Madrid: Imprenta Real, 1835) que circula en la Nueva Granada.

58

COMTE, François-Louis-Charles. Tratado de legislación o exposición de las leyes generales con arreglo a las cuales prosperan, decaen o se estancanlospueblos.(1826).Barcelona:Imprenta de don Antonio Bergnes, 1836 de la inteligencia"; éstos son poderes que "el hombre artificialmente se $\mathrm{lo}[\mathrm{s}]$ ha formado $\mathrm{o}^{\prime 50}$. Esa adquisición tecnológica constituye un salto - no ya una progresión - en la naturaleza del ser humano, una transformación radical pues la tecnología suple - con su carácter artificial - la constitución natural del ser humano. En segundo lugar, el aumento de la capacidad tecnológicahamultiplicadoelpoderproductivoy"hanproducidounasociedad industrial universal" ${ }^{\prime 1}$. Como dice Caro, “... desde el momento en que, por la invención de instrumentos y máquinas de cualquier especie, cada hombre puede producircon su trabajo más de lo quenecesita en un ramo", desdeese instante aparece"la posibilidad decambio"52. En efecto, la innovación industrial permite la acumulación de capitaly la generación de recursos, abriendo la posibilidad de nuevas posibilidades sociales y materiales.

Finalmente las grandes transformaciones sociales que propenden a la unificación global también han acelerado las temporalidades locales. Ese proceso implica transformaciones de índole material y moral. En un texto contemporáneo a la Mecánica social Caro escribe que "La acción de las grandes metrópolis se sienteen todoel mundo.Laacción de Londres se siente en Bogotá, en Lima, en Cantón, en Pekín"53. Según Caro:

En esa acción entran matemáticamente, como en el sistema del mundo, dos elementos: la masa y la distancia. ... En el mundo moral la fuerza política de las ciudades tiene que vencer por medio del tiempo el obstáculo de la distancia, ... la naturaleza del terreno, lo malo de los caminos, la falta de vehículos, la diversidad de lenguas, etc. Pero (y nótese esto bien) la máquina de vapor y los progresos de la navegacióny delosferrocarrilestiendenáhacerdesaparecertantolosobstáculos... y lleva á la cuasi instantaneidad. ${ }^{54}$

De tal manera que la temporalidad no es estrictamente local, sino que también existe una temporalidad global que va adquiriendo cada día mayor incidencia sobre la configuración local. Estos tres factores - tecnología, industrialización y globalización - aceleran la vida en sociedad, democratizan el acceso a la vida política (aun si las instancias decisivas de ésta permanecen monopolizadas por unos pocos), remueven las certezas vigentes, en particular aquellas que tienen que ver con el cuerpo social, y problematizan los fundamentos morales de la vida en común. A partir de esto resulta claro que la filosofía de Caro está plenamente inscrita dentro delosritmosyaspiraciones deloquecomúnmentellamamosmodernidad.

La mecánica social le permite a Caro describir las vertiginosas transformacionessociales desupresente.Sinembargo,ellatambiénvuelve imposible una concepción deontológica de la moral. La"mecánica social", señala Caro, "no [es] una colección de preceptos, no una declamación contra los vicios, ni contra las malas costumbres", sino que se propone "observar los hechos, observar sus causas, observar la filiación entre los hechos y estas causas, observar sus efectos, observar la filiación entre los hechos y estos efectos" ${ }^{\prime \prime 5}$. Ahorabien, esimportanteseñalarquesureflexión sobreel movimientoenlasnuevassociedadesamericanasconstituyeunintentopor producir una "ciencia de la moral"56. El proyecto de abordar la moral como ciencianoresultamuydistantedeotrosesfuerzoscontemporáneos.Jeremy Bentham, por ejemplo, había intentado algo similar en su Introducción a los principios de la moral y la legislación (1780). ${ }^{57}$ Más contemporáneo, Augusto Comte había intentado"introducir en el estudio de la moral y de las leyes los métodosquetan seguray rápidamente han hecho progresara todas las ciencias físicas ${ }^{\prime \prime 58}$. Comte parte del supuesto que todo está sujeto 
59

La cita proviene de la célebre introducción de Littré al Cours de philosophie positive (Paris, 1830). Cito de la traducción de Jorge Lagarrigue, impresa con el título Principios de filosofía positiva. Santiago de Chile: Imprenta de la Librería del Mercurio, 1875. p.41.

60

CARO, José Eusebio. “Sobre el principio utilitario", originalmente publicado en el periódicobogotanoEIGranadino,números 14,15, 23 y 30 de octubre de 1842. La cita es tomada de la reimpresión en La bendición nupcial. Op. Cit., p.107.

61

CARO, José Eusebio. Capítulo I: “El hombre en movimiento". Op. Cit., p.240

62

Para una interpretación histórica de la Guerra de los Supremos, ver PRADO ARELLANO, Luis Ervin. Rebelionesenlaprovincia:laguerradelossupremos en las provincias suroccidentales y nororientales granadinas 1839-1842. Cali: Universidad del Valle, 2007; y el más reciente, GONZÁLEZ, Fernán. La guerra de los supremos (1839-1841) y los orígenes delbipartidismo.BoletíndeHistoriayAntiguedades 97, n.848 (2010).

63

CARO, José Eusebio. Sobre los principios generales de organización social que conviene adoptarenlaNuevaConstitución delaRepública. 1842. In: Idem. La bendición nupcial. Op. Cit., p.129-140. a leyes, así en el mundo físico como en el moral, para descubrir y exponer las leyes generales con arreglo a las cuales prosperan, decaen o se estancan los pueblos. Su discípulo Emile Littré lo explica mejor en un texto que Caro sin duda conocía bien: "el orden moral está colocado en la categoría de la ciencia positiva. Se trata desde luego de establecer hechos y de comprobarlosporlaobservación,enseguidadeencadenarlosapoyándose sin cesar sobre esta misma observación. Todo razonamiento que tienda a deducirlos a priori de algún axioma abstracto, es quimérico..." ${ }^{\prime 59}$.

Su posición a favor de la observación social establece una distancia crítica con la obra de Bentham, quien evalúa los hechos sociales por su efecto y bajo el criterio de su utilidad social. Precisamente el hecho que Bentham proponga un juicio a posteriori relativiza la moral pues todo evento puede ser evaluado en un momento como beneficioso y en otro como perjudicial. Para Caro el principio de utilidad "es una regla incierta, porque hace consistir la moralidad en los resultados, y los resultados son contingentes, lo cual hace igualmente contingentee incierta la moralidad que se les atribuye" ${ }^{\prime \prime 0}$. Esa regla incierta transforma lo social en un campo de enfrentamientos violentos y conducentes a la anarquía o, para decirlo en los términos que nos interesa, es responsable del agravamiento de la temporalidad precaria de la experiencia republicana.

Al ser una ciencia positiva, la moral no se puede"servir de voces apasionadas: no he querido hablar de derechos, obligaciones, justicia, virtud, crimen, moralidad; reservando la definición de estas voces para el último libro".SegúnCaro,ladescripcióncientíficadebellevarinexorablemente,sin polémicas posibles, a la conclusiónúnica, lógica einevitable delverdadero sentido de esas voces apasionadas:"Si en el último libro hablo de virtudes y vicios, de deberes y obligaciones; es sólo para definirlas, para manifestar loque significan, noloque deben significar" ${ }^{\prime 61}$.Deese modo, la moral como ciencia le permite identificar un punto de anclaje que le sustrae el carácter polémicoalaelaboraciónconceptual.Recordemosqueeraprecisamentela calidad conceptual de esas voces las que nos permitieron al comienzo de esteensayo identificarlaaparición de una nueva temporalidad que pronto se iba a revelar precaria. Esa ciencia moral constituye el mecanismo por medio del cual se puede regular la temporalidad precaria de la república.

Para resumir, el ambicioso proyecto de Caro se puede formular de la siguiente manera: justo en el momento en que la república traslada a la vida pública el espacio de la disputa - y se vuelve ésta el escenario en que se resuelve y construye la vida en común - de tal manera que el fundamento inmanente de la autoridad en el campo social se desvanece, justo en ese momento la mecánica social de Caro procura trasladar el principio moral principio fundante de la comunidad - al plano incontestable de la ciencia.

Entreesteprimeroensayo deljoven Caroysu producción posterior (en especial, a partir de 1844) ocurre la "Guerra de los Supremos" (1839-42), el primerconflictonacional desdelas guerras delaindependenciay uno delos más devastadores del siglo XIX. La guerra tuvo como causa inicial la supresión por parte del gobierno de los conventos menores en el sur del país pero pronto dio paso a la iniciativa de los caudillos, quienes movilizaron grupos populares, en especial indígenasyesclavos, contrael régimencentralista.En el nadir del conflicto el país estuvo a punto de fragmentarse. ${ }^{62}$ En carta que dirigeal presidente de la república, publicada en El Granadino en 1842, Caro identifica el país con una ladronería debido al grado de anarquía que la ha caracterizado. ${ }^{63}$ ParaCaro, las repúblicashispanoamericanas propician-por 
CARO, José Eusebio. Mecánica social. Algunas observaciones. In: POMBO, Rafael (ed.). Op. Cit. p.201.

65

CARO, José Eusebio. Sobre el principio utilitario. In: POMBO, Rafael (ed.). Op. Cit., p.100.

66

CARO, José Eusebio. La cuestión moral. Originalmentepublicadoenelperiódicobogotano Civilización, Bogotá, n.2, agosto 16 de 1849. La cita proviene de POMBO, Rafael (ed.). Op. Cit., p.144.

67

Ibidem, p.146.

68

Ibidem, p.146-147.

69

Mis cursivas. Antes de las virtudes públicas, vienen las privadas, lo que precisamente carece el pueblo suramericano, y hace que la cuestión defondoen estas repúblicas seala moral.Ibidem, p.151.

70

CARO, José Eusebio. Loc. Cit.

71

Ibidem, p.169. la ausencia de un pueblo virtuoso - un tipo de acción política que resulta desestabilizadora de la temporalidad colectiva.

Frentea ese puebloignorantela moral como ciencia tampoco ofrece el anhelado punto de anclaje. Su experiencia le dice que las sociedades americanas no sólo están en movimiento. En realidad, la Nueva Granada apenas está en formación, "ni aun en su estado fetal porque todavía está apenas en su estado caótico; apenas se está organizando"64. De su descripción rigurosa no se puede deducir ningún principio inamovible y el combate por la civilización y la vida requiere algo más que las verdades impávidas de una ciencia. En un conocido ensayo que publica ese mismo año Caro se corrige e insiste que la moral no es una ciencia sino una ley. Esta auto-críticadebeserentendidacomounadistanciamientodelpositivismo comteano:"En las ciencias físicas y en economía política, comoverdaderas cienciasqueson,solopuedenestudiarsehechosquepuedenserobservados aisladamente, y cuantas más observaciones se recogen, mayores adelantos hace la ciencia"; a diferencia de éstas, en la moral no se estudian "los hechos, sino que se va á buscar un principio anterior que los califique ${ }^{\prime \prime 5}$. El carácter deductivo de la descripción científica la volvía - como en el caso del utilitarismo - vulnerable al relativismo.

Este desplazamiento - de ciencia a mandato supremo - plantea el problema de la acción pública. Para Caro"La gran cuestión [del siglo] es la demoralizaral pueblo"66. Es una tarea específicamentehispanoamericana ya que en países como Inglaterra o los Estados Unidos los desacuerdos de orden político se hacen posibles a partir del consenso moral vigente entre los miembros de esas sociedades. En cambio, señala Caro, "hallareis que lo que separa los partidos de Venezuela y de la Nueva Granada" no es una cuestión de pareceres sobre cómo proceder al interior de las instituciones establecidas; acá lo que está en disputa "es la cuestión moral, la cuestión de orden público, la cuestión de los medios de que puede valerse la ambición, las cuestiones personales que tienen por origen y por motivo la cuestión moral"67. Por lo tanto, "La lucha es la de la seguridad contra la violencia, la del órden contra el desórden, la del gobierno pacífico y leal contra el motín y las puebladas. La lucha es la del voto con la palabra contra el voto con el puñal"68. Los llamados partidos políticos en la región no son sino fuerzas morales, ya bien a favor del orden y la conservación o a favor de la anarquía y la disgregación.

En medio del conflicto la ley necesita una expresión institucional. Es acá cuando Caro llega a su formulación más explícitamente política. Para éste no hay más que dos remedios:"o desistir del gobierno democrático, o adquirir las virtudes públicas y privadas necesarias para sobrellevar la libertad"69. Pero, continua Caro, "la razón... halla en la monarquía [y la aristocracia] inconvenientesterribles"70.Lamonarquía, porejemplo,“Esun gobierno demasiado fastuoso, demasiado caro, particularmente funesto para países nuevos, pobres y despoblados". Además la democracia -así como el desarrollo científico, el incremento de la productividad y la globalidad - resultan inevitables:"en efecto, todos los pueblos del mundo se van encaminando, con un movimiento más o menos regular, más o menos acelerado, hacia la libertad democrática"; aún más, tal "movimiento inatajable que a todos nos arrebata" en realidad ocurre "gracias al comercio, a la navegación y a la imprenta"171.

Como ya hemos visto la democracia es necesaria pero resulta difícil y peligrosa. La república es un sistema precario, inestable, en él“la causa 
72

CARO, José Eusebio. La cuestión moral. In: POMBO, Rafael (ed.). Op. Cit., p.147.

73

Ibidem, p.145.

74

Ibidem, p.149.

75

Ibidem, p.151.
76

CARO, José Eusebio. Fundar una sólida democracia... (1846). Reproducido en HERRERA SOTO, Roberto (ed.). Antología del pensamiento conservador en Colombia. Bogotá: Instituto Colombiano de Cultura, 1982. Tomo 1. p.170.

77

CARO, José Eusebio. La bendición nupcial. In: POMBO, Rafael (ed.). Op. Cit., p.47.

CARO,JoséEusebio.Proposicióndematrimonio. In: POMBO, Rafael (ed.). Op. Cit., p.44. originaria del mal es muy profunda; esa causa está en los furores sordos de la envidia, en lastentaciones ambiciosas, que soplay excita ardientemente ysindescansoen los corazones deloshombreel gobierno democrático".La democracia "aviva las pasiones" produciendo una acción disolvente en la que"el gobierno es la presa a que se aspira, y la moral del pueblo el campo que deja devastadoel combate ${ }^{\prime \prime 72}$.Es poreso quela acción del gobierno terrenal, valedor de la ley moral, consiste esencialmente en la represión permanente del mal moral por medio de la aplicación del castigo material al delitocomprobado. ${ }^{73}$ Desdeese punto devista, la represión haceposible la justicia y es la justicia simultáneamente. Pues, sin la represión moral, se pregunta Caro, ¿qué le queda a la muchedumbre ignorante y sin Dios? ${ }^{74}$

Loque senecesita en estos pueblosjóveneses"Ungobierno sencillo, barato y liberal - aunque bastante fuerte para cumplir su misión..."75. De ese modo, la tarea político moral consiste en

\begin{abstract}
Fundar la democracia: ir llamando poco a poco al pueblo a la soberanía que nunca ha ejercido; darleinstitucionesquelovayanenseñandoa procederenjunta; ponerle en las manos el instrumento, para que aprenda a manejarlo; formar sus costumbres y darle actividad; fortificar el principio religioso, entre nosotros desacreditado en unosyenotrospervertido; colocarenlamayoríaesepoderpredominante,verdadero y permanente, que hoy en ninguna parte se descubre, y cuya falta nos ha acarreado la anarquía: he aquí la única empresa posible.... ${ }^{76}$
\end{abstract}

Pero si la moral es una ley, y por lo tanto su acatamiento es el resultado dela elección personal entrela verdaderay la falsa, la responsabilidad de los ciudadanos es mantener la vigilia ante las falsas morales, una suerte de vivere civile profundamente católica. Represión y ciudadanía no son, después de todo, contradictorias sino la expresión armónica de esa verdadera ley republicana.

Así como detrás de la frágil república neogranadina existe una república fundada en la verdadera ley, asídetrás del tiempo precario existe un tiempo eterno. En 1844 Caro escribe un poema a la muerte de su padre en el que invoca la naturaleza recóndita del verdaderotiempo, no deaquel que deviene en cada instante de nuestra existencia:"Oh tiempo! Dios solo conoce tu oscuro secreto" ${ }^{\prime 77}$. Con los años, en la medida que la disputa entre liberales y conservadores se agudiza y amenaza con otra guerra civil, Caro centra el tiempo etéreo, del progreso y la contingencia, en la certeza deuntiempoeterno.Unavezmás, esensupoesía dondeencontramosuna noción más elaborada de este tiempo:

\footnotetext{
El hombre es una lámpara apagada,

Toda su luz se la dará la muerte,

Y un nuevo nombre, y una nueva suerte,

Y un nuevo ser-demonio ó serafín!

Al alma el tiempo tiene aquí tapada:

La eternidad del tiempo rompe el velo....

La eternidad !—oh Dios ! infierno y cielo! ${ }^{78}$
}

Elordenamientoeternoexplicaelreconocimientodelodiversocomo parte de la armonía, expresando un orden. En un futuro, dice Caro,

... terminará la diversidad de razas, porque la blanca absorberá y destruirá la india, la negra, la amarilla, etc. Desaparecerán las diferencias de lenguas y naciones, lo mismo que los jornaleros, porque todos serán empresarios y porque las maquinas harántodoeltrabajohumano.Desapareceránlostrabajadoresdebajacategoríayen 
80

CARO, José Eusebio. El partido conservadory su nombre. In: POMBO, Rafael (ed.). Op. Cit., p.177.

81

RAMÍREZ, Ramón. El cristianismo y la libertad. 1855. Caracas: Monte Ávila Editores, 1991. p.40.

82

POCOCK, John Greville Agard. Op. Cit., p.538. su lugar aparecerá el ingeniero moderno, es decir el hombre inteligente encargado deladirección deuna máquina,elhombrequeconstituyeelanunciovivoy profético de todos los jornaleros del mundo. ${ }^{79}$

Este tiempo - que jamás podemos llamar tradicional - es el fundamento verdadero de la ley moral y le da sentido al progreso intelectual y material. Por lo tanto, "... no es un principio que pueda proclamar un partido; el progreso es un impulso puesto por Dios en las entrañas de cada sociedad" ${ }^{\prime 80}$. La respuesta que Caro ofrece al problema de la experiencia precaria - y que, estrictamente no puede ser descrita bajo el lenguaje antinómicodemodernidadotradición-compartemuchoselementos (de léxico, de argumento, ílocucionales, etc.) con una muy buena parte de la segunda generación de republicanos americanos. El venezolano Ramón Ramírez, por ejemplo, escribía en 1855: "el orden ..., cuya conservación constituye el objeto de la sociedad civil, no es el reposo, producido por el equilibrio de fuerzas encontradas, sino antes bien, el movimiento que resulta de la armonía y combinación de las fuerzas sociales en el sentido de El Progreso EN BUSCA DE LA PERFECCIÓN, O SEA DE LA CIVILIZACIÓN".81

Desde nuestra pretendida modernidad secular el proyecto de José Eusebio Caro nos genera fascinación y a menudo lo contemplamos como un proyecto contradictorio, incluso fallido. Con Pocock tendríamos que ser más indulgentes y señalar en cambio que"estos hombres recurrieron a un lenguaje político altamente ambivalente, cuajado de matices y repleto de opciones alternativas, de conflictos y de confusiones de las que eran perfectamenteconscientesyenlasque, dealgunamanera, seencontraban atrapados" 82 . Como todos, incluso nosotros. 